\title{
Inhibition Film Formed by 2-mercaptobenzothiazole on Copper Surface and Its Degradation Mechanism in Sodium Chloride Solution
}

\author{
J. Li, C. W. Du* , Z. Y. Liu, X. G. Li, M. Liu \\ Corrosion and Protection Center, University of Science and Technology Beijing, Beijing 100083, \\ China \\ *E-mail: dcw@ustb.edu.cn
}

doi: $10.20964 / 2016.12 .46$

Received: 20 August 2016 / Accepted: 28 September 2016 / Published: 10 November 2016

\begin{abstract}
Copper surface was modified by 2-mercaptobenzothiazole (MBT) dissolved in isopropanol for the first time. The interaction between MBT and copper, the corrosion inhibition effect of film formed by MBT on copper surface together with its dynamic evolution in $3.5 \mathrm{wt} \%$ sodium chloride solution were investigated by Auger electron spectrum (AES), ex-situ Raman spectrum, open circuit potential, potentiodynamic polarization, cyclic voltammograms, electrochemical impedance spectroscopy tests, and scanning electron microscope (SEM). The results of AES and Raman spectrum show that MBT is prone to interact with copper surface to form a complex film consisting of $[\mathrm{Cu}(\mathrm{I}) \mathrm{MBT}]_{\mathrm{n}}$ (having probably polymeric nature) in isopropanol which would oxidize to degrade to form $\mathrm{Cu}$ (II) species and $(\mathrm{MBT})_{2}$ with immersion time extending in the presence of oxygen. The electrochemical tests and SEM indicate the complex film improves corrosion resistance of copper to the media containing chloride by inhibiting both anodic and cathodic reactions with interfering the transport of $\mathrm{CuCl}_{2}^{-}$and $\mathrm{O}_{2}$, and the inhibition effect of $[\mathrm{Cu}(\mathrm{I}) \mathrm{MBT}]_{\mathrm{n}}$ complex film weakens due to its oxidative degradation with immersion time increasing.
\end{abstract}

Keywords: copper; 2-mercaptobenzothiazole; corrosion inhibition; electrochemical tests; surface characterization

\section{$\underline{\text { FULL TEXT }}$}

(C) 2016 The Authors. Published by ESG (www.electrochemsci.org). This article is an open access article distributed under the terms and conditions of the Creative Commons Attribution license (http://creativecommons.org/licenses/by/4.0/). 